\title{
The effects of adding waste plastic fibers on some properties of roller compacted concrete
}

\author{
Adil Abed ${ }^{1, *}$, Abdulkader Al-Hadithi ${ }^{2}$, and Ahmed Salih Mohammed ${ }^{1}$ \\ ${ }^{1}$ University of Anbar, College of Engineering, Civil Engineering Department, Ramadi, Anbar, Iraq \\ ${ }^{2}$ University of Anbar, College of Engineering, Dams and Water Resources Engineering Department, Ramadi, Anbar, Iraq
}

\begin{abstract}
An attempt to produce of roller compacted concrete (RCC) improved by adding waste plastic fibers (WPFs) resulting from cutting the PET beverage bottles was recorded in this study. The method which is used for production of RCC is an approved design method for ACI committee (5R-207,1980)[1]. WPF was added by volumetric percentages ranging between $(0.5$ to $2 \%)$ and reference concrete mix was produced for comparison reason. Many tests were conducted on the models produced by rolling compacted concrete like compressive strength, flexural strength, modulus of elasticity, dry density, water absorption and ultrasonic pulse velocity. The analysis of the results showed that the use of plastic waste fibers (1\%) had led to improvement in the properties of each of the compressive strength and flexural strength compared with reference concrete. Results also showed that the addition of these, fibers increase water absorption and reduce the speed of Ultrasonic pulse velocity.
\end{abstract}

\section{Introduction}

Roller compacted concrete (RCC) differs from conventional concrete principally in its requirement for a zero - slump consistency at the time of mixing and placement. This allows the material to be placed in successive layers using earth moving construction methods, When vibratory compaction adds to these individual layers, the resulting material exhibits comparatively high compressive strengths relative to the quantities of Portland cement used in the mixture, In addition, RCC mixtures are often able to utilize marginal aggregates which could not be tolerated in conventional concrete mix designs [2]. Batayneh et al. [3] Studied the effects of ground plastic on the properties of concrete. Concrete mixes containing plastic particles which were partially proportioned replaced with fine aggregate up to $20 \%$. They concluded that the addition of plastic particles led to a reduction in the strength properties. Many researchers [4], [5] studied the effects of adding waste plastics as aggregates or as fibers on the properties of RRC. All these researches proved that, the addition of WPFs led to an increment in compressive strength because of the fibers increase of interlocking among the matrix and reduce cracking development during loading. The aim of this research is studying the effect of adding waste plastic fibers, which are produced from the cutting by hand of plastic beverage bottles on the properties of RCC.

* Corresponding author: adil eng2005@yahoo.com

\section{Experimental program}

\subsection{Materials}

Ordinary Portland cement has been used in casting all specimens throughout the experimental work. Physical and chemical analysis and tests proved that, this kind of cement conforms to the Iraqi Specifications I.Q.S. $5 / 1984$ [6]. For preparing mixes, natural sand is used with a maximum aggregate size of $4.75 \mathrm{~mm}$. The sieve analysis and physical properties of this aggregate conforms to the Iraqi Specifications I.Q.S. No.45/1984 zone 2[7]. Crushed gravel is used for preparing mixes with a maximum size of aggregate equal to $14 \mathrm{~mm}$. The sieve analysis and physical properties of this aggregate proved that, this aggregate conforms to the Iraqis specifications I.Q.S. No.45/1984.

The water, which is used for both mixing and curing is potable water from the water-supply network system (tap water). The geometrical characteristics of WPFs throughout the experimental work are illustrated in Table(1). 


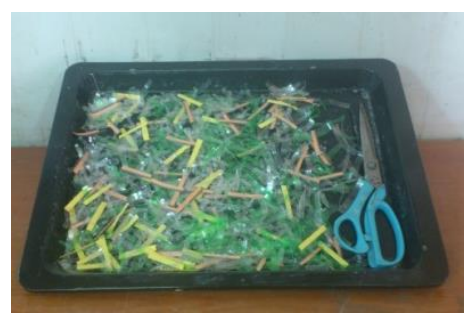

Figure 1. Waste domestic plastics are made into fiber

Table 1. Characteristics of plastic fibers

\begin{tabular}{|c|c|c|c|c|}
\hline $\begin{array}{l}\text { Type of } \\
\text { Fibers }\end{array}$ & $\begin{array}{l}\text { Average } \\
\text { Length } \\
(\mathrm{mm})\end{array}$ & $\begin{array}{l}\text { Average } \\
\text { Width } \\
(\mathrm{mm})\end{array}$ & $\begin{array}{l}\text { Average } \\
\text { Thickness } \\
(\mathrm{mm})\end{array}$ & $\begin{array}{l}\text { Specific } \\
\text { gravity }\end{array}$ \\
\hline $\begin{array}{c}\text { Plastic } \\
\text { fibers }\end{array}$ & 30 & 4 & 0.30 & 1.12 \\
\hline
\end{tabular}

\subsection{Testing moulds}

Standard Cylindrical mould of $150 \mathrm{~mm}$ diameter and $300 \mathrm{~mm}$ height is used to prepare the test specimens .Cubic moulds of $100 \mathrm{~mm}$ and $150 \mathrm{~mm}$ have been used for some of other testing specimens .Prisms moulds of $(100 \times 100 \times 500 \mathrm{~mm})$ are used for the flexural strength testing. The results are modified to obtain equivalent values as for cylinder specimens.

\subsection{Equipments which used for production of RCC samples}

Modified hammer conforming to ASTM D-1557 (modified proctor, weighted $4.5 \mathrm{~kg}$ ) was used for compaction of RCC materials, into testing moulds. The vibrating compaction hammer with a minimum mass (without tamping plate) of $10 \pm 0.2 \mathrm{~kg}$ a shown in Fig (2).It also has minimum power input of 900 Watt and capable of providing at least 2000 impacts /min. Tamping plate: A circular steel plate attached to a metal shaft, which insert into the vibrating hammer chuck. The diameter is $140 \pm 3 \mathrm{~mm}$ and a mass of $3 \pm 0.1 \mathrm{~kg}$.
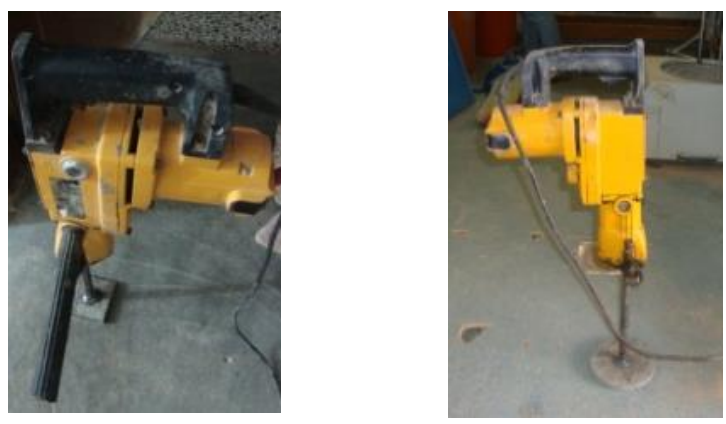

Figure 2. Vibrating compaction Hammer with tamping plate

\subsection{Mixes}

In order to select the mixture proportion for RCC, the design method recommended by ACI committee 207-
$5 \mathrm{R}, 1980$ [8], is adopted .The weights of the materials per cubic meter of RCC are:

\begin{tabular}{|l|l|}
\hline Material & Weight $\left(\mathrm{kg} / \mathrm{m}^{3}\right)$ \\
\hline Ordinary cement & $202-355$ \\
\hline Water & $114-160$ \\
\hline Aggregate & $2020-2090$ \\
\hline
\end{tabular}

Therefore it is decided to use the mix which contains 329 $\mathrm{kg} / \mathrm{m}^{3}$ cement and water/cement ratio 0.4 as fixed mix proportions, at the same time the aggregate content is $2060 \mathrm{~kg} / \mathrm{m}^{3}$ where the gravel is $927 \mathrm{~kg} / \mathrm{m}^{3}$ and the sand is $1133 \mathrm{~kg} / \mathrm{m}^{3}[8]$.

\subsection{Preparation of specimens}

The specimens of RCC are prepared by using Cylindrical steel moulds of size $(150 \times 300 \mathrm{~mm})$, cubes of size $(100 \times 100 \times 100 \mathrm{~mm})$ and prisms of size $(100$ $\times 100 \times 500 \mathrm{~mm}$ ) for most testing which is carried out throughout this work. Before casting, the moulds are cleaned, rigidly tightened, and lightly oiled to prevent concrete sticking to them. After mixing, the materials are placed by filling these cylinders, cubes and prisms in three layers and compacted by placing the hammer with tamping plate on concrete. After that, vibrating by the hammer will be started allowing the concrete to compacted under the tamping plate. The observation should be taken of the concrete in the annular space, in the region between tamping plate edge and in the insider wall of the mould. When the concrete consolidates, mortar should fill in the annular space between the outer edge of the tamping plate and the inside mould wall.

Until the mortar forms a ring round the total primeter of the tamping plate, this mortar should be observed. The vibrating hammer should be stopped, when the mortar ring forms complete the tamping plate according to ASTM C-1435[10].

\section{Results and discussions}

Figure 3. illustrate the dry density and moisture content relationships for the same samples. It can be seen that the dry density increases with increasing moisture content until it reaches an optimum, then the dry density decreases with further increase in moisture content. 15\% cement content (as percentage of total dry aggregate weight) gives the maximum dry density of $2.324 \mathrm{~g} / \mathrm{cm}^{3}$ at $5.5 \%$ moisture content. 


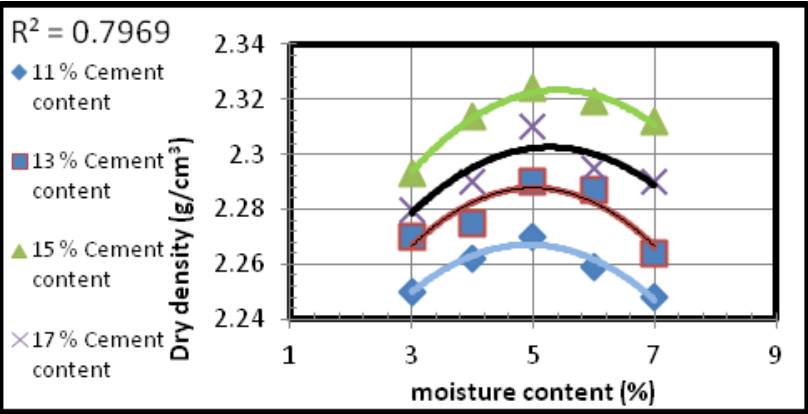

Figure 3. Relationships between dry density and moisture content.

\subsection{Effect of volume fraction of plastic fibers on the mechanical properties of RCC.}

The compressive strength is determined by using cylinder specimens according to ASTM C-39 2003[11]. Figure 4. shows the relationship between compressive strength with WPFs. The compressive strength increases from plastic fibers ratio of $(0 \%)$ up to ultimate compressive strength at plastic fibers of $(1 \%)$ then the strength decreases as plastic fibers ratio increases at any curing age. The reduction in compressive strength beyond the optimum (plastic fibers) of (1\%) may be due to decrease in workability factor, this leads to resistance in that the compaction process and not to obtain fully compacted mixture. The ultimate compressive strength at $(7,14$ and 28$)$ days is higher by $(41.2,48.5$ and $52.153 \%$ ) respectively, than the compressive strength at plastic fibers ratio of $(0 \%)$.

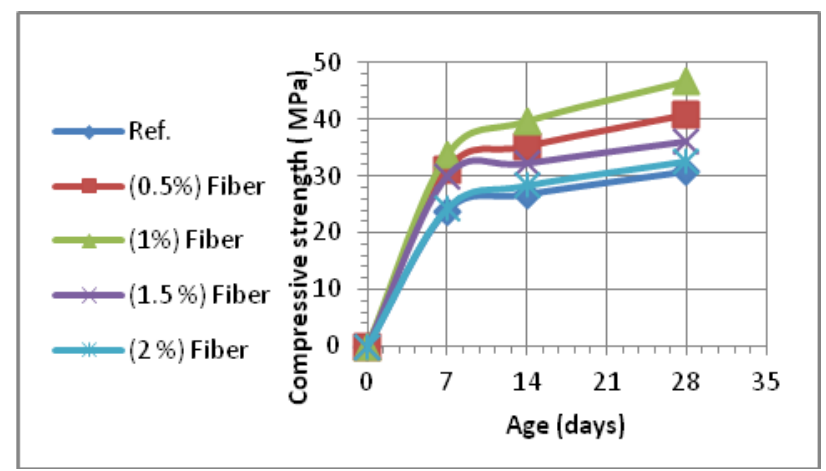

Figure 4. The relationship between compressive strength of RCC mixes with age.

Determination of the modulus of elasticity for each mix was done according to ASTM-C-469 2002[12]. Figure 5. shows the effect of volume fraction of plastic fibers on the static modulus of elasticity of RCC at 28 days. It can be seen that there is a significant increase in the static modulus of elasticity with the increase in the volume fraction of plastic fibers up to $(1 \%)$ by volume. The average increase is higher by $(44.73 \%)$ than the static modulus of elasticity at plastic fibers ratio of $(0$ $\%)$.

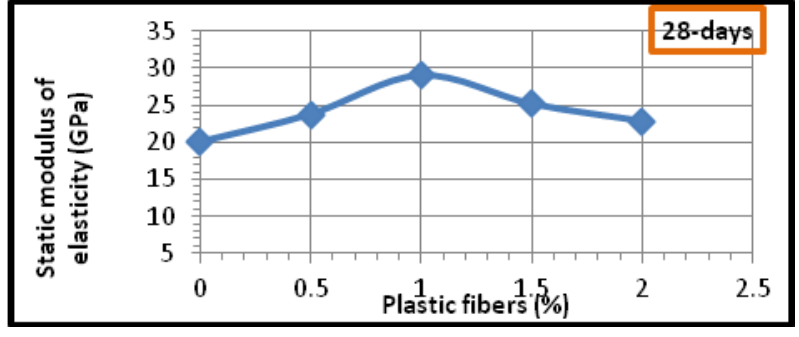

Figure 5. Variation in static modulus of elasticity with WPFs in (28 days)

The flexural strength of the $(100 \times 100 \times 500 \mathrm{~mm})$ specimens are determined by applying center point loading of sample beam according to ASTM C-293 2003[13].The effect of volume fraction of plastic fibers on the Flexural Strength (ultimate flexural Strength) of RCC specimens at (7, 14 and 28) days is shown in Figure 6 . It can be noticed that the flexural strength increases with the increase of plastic fibers up to $(1 \%)$ .The ultimate flexural strength at 28 days is higher by $(17.86 \%)$ than the flexural strength at (plastic fiber) ratio of $(0 \%)$. The flexural strength increases because the plastic fiber works bridging among materials during applied load.

\subsection{Absorption of water}

According to ASTM C-642 1997[14], The water absorption test is carried out using cubic moulds $(150 \mathrm{~mm})$. The relationship between the plastic fibers and absorption of RCC mixes is presented in Figure 7. It can be noticed that the absorption increases with the increase of fiber content to $(1.5 \%)$. The reason for this is the irregular distribution of fibers when increasing the volumetric ratios of fiber and this leads to roll and increase air voids under the lamellar body of the waste plastic fibers[15]. As shown in the same figure, it can be seen that, after approximately $(1.5 \%)$ plastic fibers, the mix begins to have absorption less than of the mix that has $(1.5 \%)$ plastic fibers where the rate of increase until( $1.5 \%)$ lies between $(16.95 \%$ to $35.37 \%)$ from the reference mix.

\subsection{Ultrasonic pulse velocity (UPV)}

This test was performed according to ASTM C597 09[16]. Figure 8. shows that the pulse of RCC decreases with the increase of the plastic fiber ratio. The decrease in pulse velocity is slight, where this decrease is because finding plastic fibers in the mix where this fiber works on the extinction the wave and this gives rise to deficiency in time of wave transfer between specimens terminal. As shown in the same Figure it can be seen at approximately $(2 \%)$ that plastic fiber is decreased $(1.45 \%)$ than the mix that has $(0 \%)$ plastic fiber. 


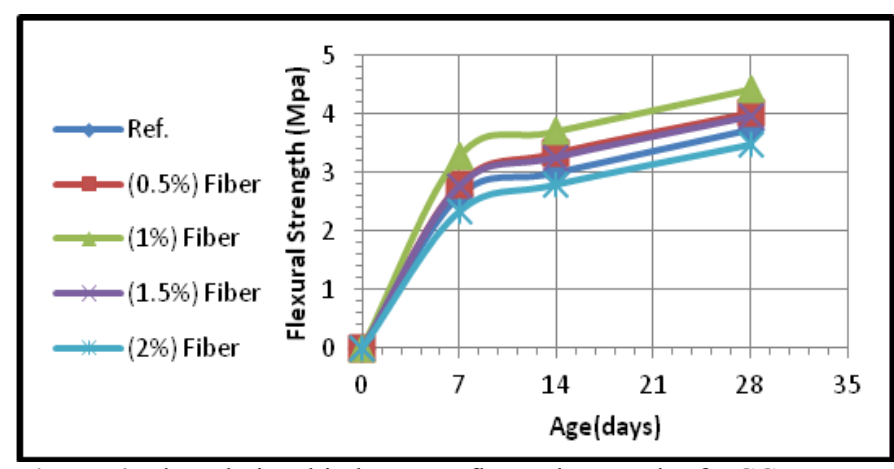

Figure 6. The relationship between flexural strength of RCC mixes with age.

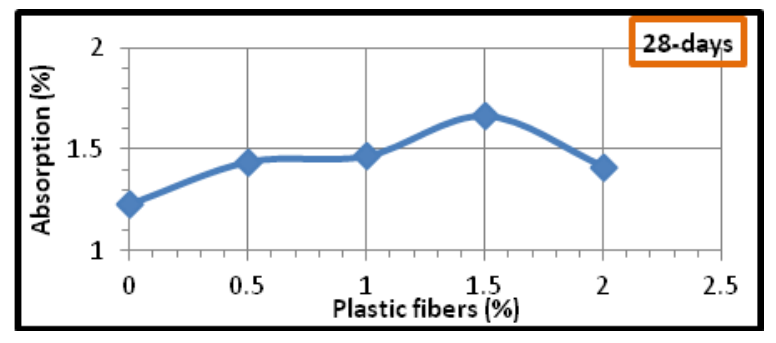

Figure 7. Variation in absorption with a WPFs ratio of RCC mixes in (28 days).

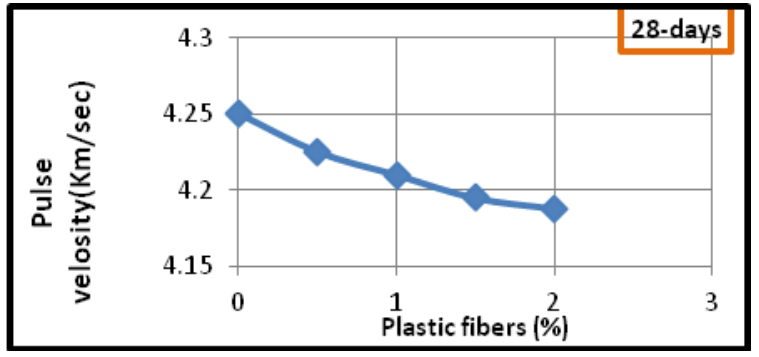

Figure 8. Variation in pulse velocity with WPFs ratio of RCC mixes in (28 days).

\section{Conclusions}

The compressive strength of RCC depends mainly on the water/cement ratio, cement content and degree of compaction.

- It is shown that the optimum water/cement ratio is (0.4) for the mix adopted throughout this investigation.

- Compressive strength for RCC mixes increases with the addition of plastic fiber to the reference mix as a percentage of the mix. Compressive strength increases until (plastic fiber) ratio reaches an optimum value (1\%) and it is higher by $(52.15 \%)$ than the compressive strength of (plastic fiber) of 0 $\%$ at 28 days.

- The flexural strength increases with the an increment of WPFs ratio, and the ultimate flexural strength at 28 days is higher by $(17.86 \%)$ than the flexural strength at (plastic fiber) ratio $(0 \%)$.

- The porosity and absorption increases with the increase of the percentage of plastic fiber where the rate of increase until (1.5\%) plastic fiber between (10.12 to $52.4 \%$ ) and ( 16.95 to $35.37 \%$ ) for porosity and absorption respectively.

- The pulse velocity of RCC decreases with the increase of the plastic fiber ratio; at approximately $(2 \%)$ plastic fiber was decreased to $(1.45 \%)$ than the mix that has $0 \%$ plastic fiber.

\section{References}

1. ACI Committee 207, (ACI-207 5R-80),ACI, 1980.

2. K. D. Hansen, Concr Int J, Vol. 9, No. 2, pp.15-17, Feb. ,1987.

3. M. Batayneh, I. Marie and I. Asi, Waste Manag . Vol. 12, No. 27, pp. 1870-1876, 2007.

4. Piggott, R.W, PCA R \& D serial No.2261, Portland cement Association, Skokie, Illinois, USA, PP. 62, 1999.

5. E. Reid and J. Marchand, Nova Scotia, 1998.

6. Iraqi specifications - $\mathrm{No}(45)$, Ministry of Planning, Baghdad, Iraq,1999.

7. Iraqi standard specification- $\mathrm{No}(5)$, Ministry of Planning, Baghdad, Iraq, 1999.

8. ACI Committee 207-5R-96, ACI Manual of Concrete Practice, part (1), 1-49, 1996.

9. ASTM D1557, Annual Book of ASTM Standards, Vol. (04.08), West Conshohocken, PA., United States, 2002.

10. ASTM D1435, Annual Book of ASTM Standards, Vol. (04.08), West Conshohocken, PA., United States, 2009.

11. ASTM C39/C39M-01, Vol. 04.02), West Conshohocken, PA., Issued October 2003.

12. ASTM C469-02, Annual Book of ASTM Standards, Vol. (04.02), West Conshohocken, PA., Issued October 2003.

13. ASTM C293, Annual Book of ASTM Standards, Vol. (04.02), West Conshohocken, PA., Issued October, 2002.

14. ASTM C642 (1997), "Standard Test Method for Density, Annual Book of ASTM Standards, West Conshohocken, PA., Issued October.

15. A. I. Al-Hadithi and W. K. Frhaan, Iraqi J. of Civil Eng., Vol. 11, No. 1, pp.1-20,2017.

16. ASTM C597-09, Annual Book of ASTM Standards, West Conshohocken, PA., 2009. 